\title{
The Studies on Cestodes in China
}

\section{Cheng Gonghuang*}

Fisheries College, Guangdong Ocean University, Zhanjiang, 524025, China

\begin{abstract}
Cestode studies carry out in China for about 80 years since the earliest paper published by Shen Tseng and after then a lot of works have been done and there comes many good results as total about 400 species with many new were reported and described. All the works have been reviewed here by author and it is known that a big work called "Cestodology" will be published the next year.
\end{abstract}

\section{Keywords: Cestode; Study; Taxonomy; China}

Cestodes are a lot of parasites that parasitized in human and other animals. They belong to phylum-Platyhelminthes, Class-Cestoda. It is known to make human diseases when they parasitized in a human body in the Sui Dynasty (1700 years ago) and after then a lot of the cestodologists in China did a relative wide range research in cestode taxonomy in China [1,2]. Most of the authors are parasitologists who do a large field research concerning to cestodes. At the present the most famous researchers in China are Lin in South and Yun in North, both of them are great cestodologists in this field and did a lot of wild research works, reported a lot of new cestoda species in China. Lin et al. $[3,4]$ $\mathrm{Lin}$ and $\mathrm{Li}$ [5] also did some research in the life-cycles of a few species and made a great progress in the cestodology in China. But there had been even no any research book in this field in China by 2002 so the author presented one called "Studies on the cestodes in China" which contained all his research in cestodology and the works were done not so satisfactory. And what he wants is that after this simple work there may follow a lot of good jobs that could make this study in China more completed in the future. It is now comforting that a work with 4,000,000 words called "Cestodology" in Chinese will be published the next year!

In the book of "Studies on the cestodes in China" the author had done the following works:

In this book there are some research works focus in the taxonomy of reptiles, fish and mammals with a few of birds.

The author compared the ultra-morphology of the cestoda with that of the insect with medical importance and got the result that at high stage of protostomes (insecta, for example, Periplaneta americana) differentiate much more than the lower ones (cestoda, such as Anomotaenia amaurornisus) in morphology structure of the body and function of recepors. With the SEM the author also observed that the cestode has at least 2 types of sensilla in the scolex and this make a question on the present text book of "General Zoology" in China. So this may give some new thoughts for scholars in the field of cestodology. The author thinks that at the present the cestode research work in China almost are at the same level all over the world as Liao and Lun [6] did some job with the molecular biology method to determine the phylogeny between species of the genus Bothriocephallus.

This paper introduces the cestode research, especially taxonomic studies, its present condition and history. Faust and Wassell [7] had done parasite research in China including cestode. Chinese scientists studied a little late than foreigners. Earliest one is $\mathrm{Hu}$ et al. [8] did the work about cysticercoid parasitic in human, and that was the commence research of human cestode in China. The taxonomy research of cestode began in 1930s, Tseng $[9,10]$ and Hsü [11] ever studied the cestode of birds and other animals, systematically.
Then a lot of scientists such as Li SY [1], Gu [2], Lin and Li [5] did the cestodes of investigation of domestic fowls and beasts. Yeh [12], Liao and Shi [13], Chen Y [14], Wang XY [15], Tang CC [16], Wang PQ [17] reported a series of fish cestodes in China. Xu et al. [18] and Kong and Yin [19], Wu SQ [20], Yang P [21], Lin Y [22], Lin et al. [23] had investigated, described and reported cestodes of domestic beasts.

In 1970s-1980s Lin et al. [3-5,22,23] had done a lot of research work about wild life cestodes with new species reports.

Now cestode studies in our country have reached a scale that shows high level research work: several kinds of cestode lifecycle research have been completed and have been used in the practice and improved the agricultural production. Microscopy research have also been done, systematic studies on parasite include cesotde everywhere in China, Liao and Lun [24] have some molecular biological studies on cestode taxonomy, and it is early work all over the world. But the fundamental research works in China are still lacking, especially wild life cestode research very few take fish and reptile as examples. The cestodes of reptiles only Hsü's [11] report Ophiotaenia nankingensis, Ophiovalipora houdemeri and Oochoristica hainanensis can be seen except recent work by Cheng GH [25]. There is still very hard work for Chinese cestodologists to do for wild life research works to discover all the species of the cestodes in China.

It was estimated by Lin Y [26] there are about 213 species of cestodes in China but it reaches about 400 counted by Cheng GH [25] All these calculations did not show the actual level of it in China as we know China have about $1 / 10$ of species in the world but we don't reach because the cestodes described in the world have been reached more than 4000 species and the cestode species can go around the world by the migration of birds so that the cestode species China should have more.

Our record of cestode species have $6.6 \%$ unidentified species is because lacking of documents and incomplete worms collected. By early systematic method cestodes in China are belonging to 9

*Corresponding author: Cheng Gonghuang, Fisheries College, Guangdong Ocean University, Zhanjiang, 524025, China, Tel: +8613828291964; E-mail: ghcheng@sohu.com

Received October 27, 2013; Accepted December 18, 2013; Published December 23, 2013

Citation: Gonghuang C (2013) The Studies on Cestodes in China. J Veterinar Sci Technol 5: 150. doi:10.4172/2157-7579.1000150

Copyright: $\odot 2013$ Gonghuang C. This is an open-access article distributed unde the terms of the Creative Commons Attribution License, which permits unrestricted use, distribution, and reproduction in any medium, provided the original author and source are credited. 
orders: 1. Proteocephalidea Mola; 2. Cyclophyllidea van Beneden in Braun; 3. Caryophyllidea van Beneden in Carus; 4. Pseudophyllidea Carus; 5. Tetraphyllidea Carus; 6. Trypanorhyncha Diesing; 7. Lecanicephalidea Baylis; 8. Spathebothriidea Wardle McLeod; 9. Nippotaeniidea Yamaguti.

\section{Acknowlegement}

The author thank to his tutor Prof. Lin Yuguang, Life Sciences School, Xiamen University, for his kindly guidance for entrance to cestodology research.

\section{References}

1. Li SY, Chow CY, Hsu HF (1948) Helminths of chickens in Peiping, China. Peking Nat Hist Bull 16: 215-219.

2. Gu CD (1958) Helminths of domestic chickens. Bulletin of Biology 5:1-9.

3. Lin YG, Guan JZ, Wang PP, Yang WC (1982) Studies on the developmental cycle of Paranoploce. Phala ryjikovi Spassky, 1950 in the intermediate host. Current Zoology (Acta Zoologica Sinica) 28: 262-271

4. Lin Y, Guan JZ, Wang PP, Yang WC (1982) On the developmental cycle of the marmot cestode, Paranoplocephala transversaria (Krabbe, 1879) in the intermediate host.Current Zoology (Acta Zoologica Sinica) 28: 368-376

5. Lin YG, Li G (1984) Studies on fauna of domestic chicken in Fujian. Wuyi Science4: 85-102.

6. Liao XH, Lun ZR (1998) Taxonomy and relatives studies for Bothriocephalus opsariichthydis parasitic in grass carp, carp and opsariichthyd in China. Science Bulletin 43: 1073-1076.

7. Faust EC, Wassell CM (1921) Preliminary Survey of the Intestinal Parasite of man in the central Yantze Valley. China Med J 35: 1-30.

8. Hu CK, Khaw K, Frazier CH (1930) Subcutaneous Cysticercosis cellulosaein Man. Arch Derm Syph 21: 777-789.

9. Tseng S (1932) Studies on Avian Cestodes from china. Part I. Cestodes from charadriiform Birds. Parasit 24: 87-106.

10. Tseng S (1933) Studies on Avian Cestodes from China. Past II. Cestodes from charadriiform Birds. Parasit 24: 500-511.

11. Hsü HF (1935) Contributions to the study of China Cestoda. Rev Suisse Zod Tome 42: 477-570.
12. Yeh LS (1955) On a new tapeworm Bothriocephalus gowkongensis $N$. $\mathrm{Sp}$.(cestoda: Bothriocephalidae) from freshwater fish in China. Current Zoology 7: $69-74$

13. Liao XH, Shi LZ (1956) A fry disease of Guangdong, the life-cycle, ecology and prevention of Bothriocephalus gowkongensis. Bulletin of Hydrobiology 2: 129-186.

14. Chen $Y(1964)$ Fauna and taxonomy of fish parasitic helminthus - cestode part

15. Wang XY (1982) Studies on human and animal parasitic helminths Part I Fishes' heminthus parasites in Poyang Lake. Jiangxi Society of Animals and Plants.

16. Tang CC (1982) Developmental studies on Polyonchobothrium ophiocephalina (Tseng, 1933) and Bothriocephalus opsariichthydis Yamaguti, 1934. Acta Zoologica Sinica 28: 53-59.

17. Wang PQ (1984) Description of several fish cestodes in Fujian province and the catalogue of fish cestodes in China. Wuyi Science 4: 71-83

18. Xu ST, Wang XE, Lin MC (1958) Investigation report on sheep helminths of Wuwei county, Gansu province. Journal of Chinese Veterinary Science 3: 7783.

19. Kong FY, Yin PY (1959) Catalogue of parasites from Eastern area of Qinhai province. Chinese Journal of Veterinary Science 8: 248

20. Wu SQ (1960) Economic Fauna of China - Parasitic worms.

21. Yang $P$ (1962) A species of Avitellinacen tripunctata (Rivolta, 1874) from sheep in Gansu province. China Animal Husbandry \& Veterinary Medicine 8: 9-10.

22. Lin Y (1962) Studies on the development of Monieziaexpansa (Rudolphi,1810) and its intermediate host. Journal of Fujian Normal College 2: 45-68.

23. Lin YG, Ho YC, Sung YL (1975) Studies on the epidemiology of Monieziasis (Moniezia expansa) and the biology of its natural vectors. Acta Zoologica Sinica 30: $254-260$

24. Liao XH, Lun ZR (1998) Taxonomy and relatives studies for Bothriocephalus opsariichthydis parasitic in grass carp, carp and opsariichthyd in China Science Bulletin 43: 1073-1076.

25. Cheng GH (2002) Studies on the cestodes in China. China Women Publishing House. Beijing.

26. Lin Yuguang (1979) Catalog of Cestodes in China, memoir of the meeting for Cestoda fauna in China 